\title{
Torsional vibrations of infinite composite poroelastic cylinders
}

\author{
S.Ahmed Shah ${ }^{1}, \quad$ M.Tajuddin ${ }^{2 *}$ \\ ${ }^{1}$ Department of Mathematics, Deccan College of Engineering and Technology Hyderabad, INDIA \\ ${ }^{2 *}$ Department of Mathematics Osmania University, Hyderabad, INDIA \\ "Corresponding Author: e-mail: taj_osmania@yahoo.co.in
}

\begin{abstract}
A study of torsional vibrations of an infinite composite poroelastic circular solid cylinder made of two different materials is made. The frequency equation of such torsional vibrations is obtained following analytical model based on Biot's theory of wave propagation in liquid saturated porous media. Each dilatation of the solid and the liquid media is zero and therefore the frequency equation of torsional vibrations is same for pervious and impervious surfaces. The plots of non-dimensional frequency versus ratio of thickness of casing to the wavelength for two composite poroelastic cylinders are presented, and then discussed. The displacements of second and third torsional modes are determined and presented graphically for the ratio of radius of composite poroelastic solid cylinder to the radius of the inner solid cylinder. Results of previous works are shown as special case of the present analysis. By ignoring liquid effects, the results of purely elastic solid are obtained.
\end{abstract}

Keywords: Biot's theory, torsional vibrations, composite poroelastic cylinder, frequency equation, first torsional mode.

\section{Introduction}

Employing linear theory of elasticity, Gazis $(1958,1959)$ studied the plane-strain vibrations and three dimensional wave propagation in hollow elastic cylinders of infinite extent. McNiven et al. (1963) studied dispersion of axially symmetric waves in composite elastic rods of infinite extent. Armenakas (1965) discussed the torsional waves of an elastic composite infinite circular solid rod of two different materials. Using the analytical model based on Biot's theory (1956) of wave propagation in liquid filled porous media consists of an elastic solid with inter connected spaces called pores saturated with liquid, Tajuddin and Sarma (1980) studied the torsional vibrations of an infinite poroelastic solid cylinder. Tajuddin (1982) studied the torsional vibrations of a finite composite poroelastic cylinder of two different materials, either concentric or bonded end to end. Coussy et al. (1998) presented two different approaches to deal with the mechanics of deformable porous medium. Dynamic poroelasticity of thinly layered structures was given by Gelinsky et al. (1998). Degrande et al. (1998) studied the wave propagation in layered dry, saturated and unsaturated poroelastic medium. Yeheskel and Tevet (2000) presented a new assessment method to determine the bulk modulus and Poisson's ratio of porous ceramics. Wisse et al (2002) presented the experimental results of guided wave modes in porous cylinders. Malla Reddy and Tajuddin $(2003,2006)$ studied the edge waves in poroelastic plates under plane-stress conditions and cylindrical stress waves in poroelastic flat slabs. Chao et al (2004) studied the shock-induced borehole waves in porous formations. Tajuddin and Ahmed Shah $(2006,2007)$ studied the circumferential waves and torsional vibrations of infinite hollow poroelastic cylinders in presence of dissipation.

In the present analysis, the composite poroelastic solid circular cylinder of infinite extent consists of an inner solid circular cylinder of one material bounded by and bonded to a circular casing made of another poroelastic material is considered. Let the inner poroelastic solid cylinder, called core of radius $r_{1}$, bounded by and bonded to concentric outer shell known as casing of radius $\mathrm{r}_{2}$ be taken to study the torsional vibrations. Each the core and the casing of the composite cylinder are isotropic and homogeneous and infinite in length. The frequency equation of such vibrations is derived and discussed. The plots of non-dimensional frequency versus wavelength for thin and thick casing are presented. Also normalized displacements are determined and presented graphically for second and third torsional modes. This is shown for ratio of radius of composite poroelastic cylinder to radius of inner solid cylinder each for two types of composite poroelastic cylinders. Results of previous works are shown as special case of 
the present study. By ignoring liquid effects, the results of purely elastic solid are degenerated as a particular case studied by Armenakas (1965).

The study of torsional vibrations is of importance, both from theoretical and practicable consideration. Such vibrations, for example, are used in delay lines. Further based on reflections and refractions during the propagation of a pulse imperfections can be identified. Still another use is the measurement of shear modulus.

\section{Governing equations}

The equations of motion of a homogeneous, isotropic poroelastic solid in presence of dissipation (b) following Biot (1956), are

$$
\begin{aligned}
& N \nabla^{2} \vec{u}+(\mathrm{A}+\mathrm{N}) \nabla \mathrm{e}+\mathrm{Q} \nabla \in=\frac{\partial^{2}}{\partial \mathrm{t}^{2}}(\overrightarrow{\tau \mathrm{u}}+\beta \overrightarrow{\mathrm{U}})+\mathrm{b} \frac{\partial}{\partial \mathrm{t}}(\overrightarrow{\mathrm{u}}-\overrightarrow{\mathrm{U}}), \\
& \mathrm{Q} \nabla \mathrm{e}+\mathrm{R} \nabla \in=\frac{\partial^{2}}{\partial \mathrm{t}^{2}}(\overrightarrow{\mathrm{u}}+\eta \overrightarrow{\mathrm{U}})-\mathrm{b} \frac{\partial}{\partial \mathrm{t}}(\overrightarrow{\mathrm{u}}-\overrightarrow{\mathrm{U}}),
\end{aligned}
$$

where $\overrightarrow{\mathrm{u}}$ and $\overrightarrow{\mathrm{U}}$ are solid and liquid displacements; $\nabla^{2}$ is Laplace operator and e, $\in$ are the dilatations of solid and liquid media respectively. A, N, Q, R are all the poroelastic constants; and $\tau, \beta$ and $\eta$ are the mass coefficients following Biot (1956).

The stresses $\sigma_{\mathrm{ij}}$ and the liquid pressure $\mathrm{s}$ are given by

$$
\begin{aligned}
\sigma_{i j} & =2 \mathrm{Ne}_{i j}+(\mathrm{Ae}+\mathrm{Q} \in) \delta_{\mathrm{ij}}, \quad(\mathrm{i}, \mathrm{j}=\mathrm{r}, \theta, \mathrm{z}) \\
\mathrm{s} & =\mathrm{Qe}+\mathrm{R} \in,
\end{aligned}
$$

where $\delta_{\mathrm{ij}}$ is the well-known Kronecker delta function.

\section{Solution of the problem}

Consider a composite infinite solid homogeneous, isotropic poroelastic cylinder with the radii of the core and casing $r_{1}$ and $r_{2}$, respectively. The subscript ' 1 ' and ' 2 ' are used to denote the two materials of the composite cylinder. The quantities with the subscript ' 1 ' refer to the core while ' 2 ' refer to the casing. The poroelastic constants of the considered problem are ${ }_{m} \mathrm{~A},{ }_{\mathrm{m}} \mathrm{N},{ }_{\mathrm{m}} \mathrm{Q}$, ${ }_{\mathrm{m}} \mathrm{R}, \quad(\mathrm{m}=1,2)$. Let $(\mathrm{r}, \theta, \mathrm{z})$ be the cylindrical polar coordinates such that $\mathrm{z}$-axis coincides with the axis of the cylinder. The only non-zero displacement functions of solid and liquid are $\overrightarrow{\mathrm{u}}(0, \mathrm{v}, 0)$ and $\overrightarrow{\mathrm{U}}(0, \mathrm{~V}, 0)$ where

$$
{ }_{\mathrm{m}} \mathrm{V}={ }_{\mathrm{m}} \mathrm{h}(\mathrm{r}) \mathrm{e}^{\mathrm{i}(k+\omega t)}, \quad{ }_{\mathrm{m}} \mathrm{V}={ }_{\mathrm{m}} \mathrm{H}(\mathrm{r}) \mathrm{e}^{\mathrm{i}(k++\omega t)}, \quad \mathrm{m}=1,2 .
$$

Here $\mathrm{m}_{\mathrm{V}}$ and $\mathrm{m}_{\mathrm{m}} \mathrm{V}$ are functions of $\mathrm{r}, \mathrm{z}$ and time $\mathrm{t}$. Also each of the longitudinal wavenumber $\mathrm{k}$ and the circular frequency $\omega$ are identically same for both materials of the composite cylinder since they are bonded at the interface $r=r_{1}$.

From equation (3) it can be seen that the normal strains $e_{r r}, e_{\theta \theta}$ and $e_{z z}$ are all zero each for the core and the casing. Hence the dilatation (sum of normal strains) of solid and liquid is zero for both the core and the casing of the composite poroelastic cylinder. Therefore the waves considered are essentially shear waves. Since each of the dilatations of solid and liquid are zero, the liquid pressure ${ }_{\mathrm{m}} \mathrm{s},(\mathrm{m}=1,2)$ developed in the solid-liquid aggregate following equation (2) is zero. Then the equations of motion reduces to

$$
\mathrm{N}\left(\nabla^{2} \mathrm{v}-\frac{\mathrm{v}}{\mathrm{r}}\right)=\frac{\partial^{2}}{\partial \mathrm{t}^{2}}(\tau \mathrm{v}+\beta \mathrm{V})+\mathrm{b} \frac{\partial}{\partial \mathrm{t}}(\mathrm{v}-\mathrm{V}), \quad 0=\frac{\partial^{2}}{\partial \mathrm{t}^{2}}(\beta \mathrm{v}+\eta \mathrm{V})-\mathrm{b} \frac{\partial}{\partial \mathrm{t}}(\mathrm{v}-\mathrm{V})
$$

Eq.(4) with the help of Eq.(3) reduces to 


$$
\begin{aligned}
\mathrm{N} \Delta_{\mathrm{m}} \mathrm{h} & =-\omega^{2}\left[{ }_{\mathrm{m}} \mathrm{M}_{\mathrm{m}} \mathrm{h}+{ }_{\mathrm{m}} \mathrm{T}_{\mathrm{m}} \mathrm{H}\right], \\
0 & =-\omega^{2}\left[{ }_{\mathrm{m}} \mathrm{T}{ }_{\mathrm{m}} \mathrm{h}+{ }_{\mathrm{m}} \mathrm{X}_{\mathrm{m}} \mathrm{H}\right],
\end{aligned}
$$

where

and

$$
{ }_{\mathrm{m}} \mathrm{M}={ }_{\mathrm{m}} \tau-\mathrm{ib} \omega^{-1}, \quad{ }_{\mathrm{m}}^{\mathrm{T}}={ }_{\mathrm{m}} \beta+\mathrm{ib} \omega^{-1}, \quad{ }_{\mathrm{m}} \mathrm{X}={ }_{\mathrm{m}} \eta-\mathrm{ib} \omega^{-1},
$$

$$
\Delta=\frac{\mathrm{d}^{2}}{\mathrm{dr}^{2}}+\frac{1}{\mathrm{r}} \frac{\mathrm{d}}{\mathrm{dr}}-\frac{1}{\mathrm{r}^{2}}-\mathrm{k}^{2} .
$$

A solution of equation (5) gives

$$
\begin{aligned}
& { }_{2} \mathrm{~h}(\mathrm{r})=\mathrm{C}_{1} \mathrm{Z}_{1}\left({ }_{2} \mathrm{qr}\right)+\mathrm{C}_{2} \mathrm{~W}_{1}\left({ }_{2} \mathrm{qr}\right), \\
& { }_{1} \mathrm{~h}(\mathrm{r})=\mathrm{D}_{1} \mathrm{Z}_{1}\left({ }_{1} \mathrm{qr}\right),
\end{aligned}
$$

In equation (7), $Z_{1}$ denotes $J_{1}$ or $I_{1}$ i.e., Bessel or modified Bessel function of first kind and $W_{1}$ denotes $Y_{1}$ or $K_{1}$ i.e., Bessel or modified Bessel function of second kind each of order one, respectively, depending on the values of $\mathrm{m}_{\mathrm{q}},(\mathrm{m}=1,2)$ are real or imaginary, and

$$
{ }_{\mathrm{m}} \mathrm{q}^{2}=\frac{\omega^{2}}{\mathrm{~m}_{3}^{2}}-\mathrm{k}^{2}, \quad(\mathrm{~m}=1,2),
$$

where $\mathrm{V}_{3}$ is shear wave velocity (Biot, 1956). The only non-zero stress both for the core and the casing is

$$
{ }_{\mathrm{m}}\left(\sigma_{\mathrm{r} \theta}\right)={ }_{\mathrm{m}} \mathrm{N}\left[\mathrm{h}_{\mathrm{m}} \mathrm{h}^{\prime}-\left(\frac{\mathrm{m}}{\mathrm{r}}\right)\right] \mathrm{e}^{\mathrm{i}(\mathrm{kz}+\omega t)}, \quad(\mathrm{m}=1,2)
$$

where a 'prime' over a quantity denotes differentiation with respect to ' $r$ '.

\section{Frequency equation}

The boundary conditions for stress free outer surface $r=r_{2}$ and perfect bonding between the core and the casing at the interface $r$ $=\mathrm{r}_{1}$, are

$$
\begin{aligned}
& { }_{2}\left(\sigma_{\mathrm{r} \theta}\right)=0, \quad \text { at } \mathrm{r}=\mathrm{r}_{2} ; \quad{ }_{2}\left(\sigma_{\mathrm{r} \theta}\right)==_{1}\left(\sigma_{\mathrm{r} \theta}\right) \quad \text { at } \mathrm{r}=\mathrm{r}_{1}, \quad{ }_{2} \mathrm{v}={ }_{1} \mathrm{v} \quad \text { at } \mathrm{r}=\mathrm{r}_{1} . \\
& { }_{2} \mathrm{~s}=0 \text {, at } \mathrm{r}=\mathrm{r}_{2}, \quad \text { and } \quad{ }_{2} \mathrm{~s}={ }_{1} \mathrm{~s}=0 \text {, at } \mathrm{r}=\mathrm{r}_{1}, \\
& \frac{\partial\left({ }_{2} \mathrm{~s}\right)}{\partial \mathrm{r}}=0, \quad \text { at } \quad \mathrm{r}=\mathrm{r}_{2}, \quad \text { and } \quad \frac{\partial\left({ }_{2} \mathrm{~s}\right)}{\partial \mathrm{r}}=\frac{\partial\left({ }_{1} \mathrm{~s}\right)}{\partial \mathrm{r}}=0, \quad \text { at } \quad \mathrm{r}=\mathrm{r}_{1} .
\end{aligned}
$$

Equations (10) and (11) are to be satisfied for a pervious surface while equations (10) and (12) are to be satisfied for an impervious surface. Since the liquid pressure in the core and the casing is zero, therefore the equations (11) and (12) are satisfied identically. 
Substitution of (7) into (9) and (3) and then the resultant into (10) gives three homogeneous equations for three constants $\mathrm{C}_{1}, \mathrm{C}_{2}$ and $\mathrm{D}_{1}$. For a non-trivial solution to exist the determinant of the coefficients of these equations must vanish. By eliminating these constants the frequency equation of torsional vibrations is

$$
\left|\mathrm{C}_{\mathrm{ij}}\right|=0, \quad(\mathrm{i}, \mathrm{j}=1,2,3)
$$

where the elements $\mathrm{C}_{\mathrm{ij}}$ are

$$
\begin{aligned}
& \mathrm{C}_{11}=\frac{-2{ }_{2} \mathrm{~N}}{\mathrm{r}_{2}} \mathrm{Z}_{1}\left({ }_{2} \mathrm{qr} \mathrm{r}_{2}\right)+{ }_{2} \mathrm{~N}_{2} \mathrm{qZ}_{0}\left({ }_{2} \mathrm{qr}_{2}\right), \\
& \mathrm{C}_{12}=\frac{-2{ }_{2} \mathrm{~N}}{\mathrm{r}_{2}} \mathrm{~W}_{1}\left({ }_{2} \mathrm{qr} \mathrm{r}_{2}\right)+{ }_{2} \mathrm{~N}_{2} \mathrm{q} \lambda \mathrm{W}_{0}\left({ }_{2} \mathrm{qr} \mathrm{r}_{2}\right), \\
& \mathrm{C}_{23}=\frac{{ }_{1} \mathrm{~N}}{\mathrm{r}_{1}} \mathrm{Z}_{1}\left({ }_{1} \mathrm{qr} \mathrm{r}_{1}\right)-{ }_{1} \mathrm{~N}_{1} \mathrm{qZ}_{0}\left({ }_{1} \mathrm{qr} \mathrm{r}_{1}\right), \quad \mathrm{C}_{13}=0, \\
& \mathrm{C}_{31}=\mathrm{Z}_{1}\left({ }_{2} \mathrm{qr} \mathrm{r}_{1}\right), \quad \mathrm{C}_{32}=\mathrm{W}_{1}\left({ }_{2} \mathrm{qr} \mathrm{r}_{1}\right), \quad \mathrm{C}_{33}=-\mathrm{Z}_{1}\left({ }_{1} \mathrm{qr} \mathrm{r}_{1}\right), \\
& \mathrm{C}_{21}, \mathrm{C}_{22} \text { are similar expressions as } \mathrm{C}_{11}, \mathrm{C}_{12} \text { with } \mathrm{r}_{2} \text { replaced by } \mathrm{r}_{1},
\end{aligned}
$$

where $\lambda$ is

$$
\lambda=\left\{\begin{array}{lll}
+1 & \text { if } & \omega>\mathrm{kv}_{3}, \\
-1 & \text { if } & \omega<\mathrm{kv}_{3} .
\end{array}\right.
$$

Here parameter ' $\lambda$ ' is introduced in order to account the difference in sign in the recurrence relations to the derivatives of aforesaid Bessel functions, respectively. By ignoring the liquid effects in equation (13), the results of purely elastic solid considered by Armenakas (1965) are obtained.

Due to the dissipative nature of the medium, the waves are attenuated. Attenuation presents some difficulty in the definition of wave velocity, therefore we set $b=0$ in what follows. In addition, it is convenient to introduce the non-dimensional variables as follows:

$$
\begin{aligned}
& \mathrm{d}_{1}=\frac{{ }_{2} \tau}{{ }_{1} \rho} \quad \mathrm{d}_{2}=\frac{{ }_{2} \beta}{{ }_{1} \rho}, \quad \mathrm{d}_{3}=\frac{{ }_{2} \eta}{{ }_{1} \rho}, \quad \delta=\frac{\mathrm{h}}{\mathrm{L}}, \quad \mathrm{d}=\frac{{ }_{2} \mathrm{~N}}{{ }_{1} \mathrm{~N}} \\
& \mathrm{~g}_{1}=\frac{{ }_{1} \tau}{{ }_{1} \rho}, \quad \mathrm{g}_{2}=\frac{{ }_{1} \beta}{{ }_{1} \rho}, \quad \mathrm{g}_{3}=\frac{{ }_{1} \eta}{{ }_{1} \rho}, \quad \Omega=\frac{\omega \mathrm{h}}{{ }_{1} \mathrm{C}_{0}}
\end{aligned}
$$

where ' $h$ ' is the thickness of casing, $L$ is wavelength, ${ }_{1} \rho={ }_{1} \tau+2{ }_{1} \beta+{ }_{1} \eta$, and $\Omega$ is non-dimensional frequency and ${ }_{1} C_{0}$ is the reference velocity $\left({ }_{1} \mathrm{C}_{0}{ }^{2}={ }_{1} \mathrm{~N} /{ }_{1} \rho\right)$. Let

$$
\mathrm{g}=\frac{\mathrm{r}_{2}}{\mathrm{r}_{1}} \quad \text { so that } \quad \frac{\mathrm{h}}{\mathrm{r}_{1}}=\mathrm{g}-1 .
$$

Employing the non-dimensional quantities defined in equations (16) and (17), the frequency equation of torsional vibrations of a composite poroelastic cylinder (13) reduces to

$$
\left|F_{i j}\right|=0, \quad(i, j=1,2,3),
$$

where the elements $F_{i j}$ are 


$$
\begin{aligned}
& \mathrm{F}_{11}=\{x g\} Z_{0}(x g)-2 Z_{1}(x g), \quad F_{12}=\{\lambda x g\} W_{0}\{x g\}-2 W_{1}\{x g\}, \\
& F_{21}=\{x\} Z_{0}(x)-2 Z_{1}(x), \quad F_{22}=\{\lambda x\} W_{0}(x)-2 W_{1}(x), \\
& F_{23}=-(d)^{-1}\left[(y) Z_{0}(y)-2 Z_{1}(y)\right], \quad F_{13}=0 \\
& F_{31}=Z_{1}(x), \quad F_{32}=W_{1}(x), \quad F_{33}=-Z_{1}(y) .
\end{aligned}
$$

The parameter $\lambda$ appearing in (19) is defined in equation (15) and $\mathrm{x}$ and $\mathrm{y}$ are

$$
(\mathrm{g}-1) \mathrm{x}=\left[\Omega^{2}(\mathrm{~d})^{-1}\left(\frac{\mathrm{d}_{1} \mathrm{~d}_{3}-\mathrm{d}_{2}^{2}}{\mathrm{~d}_{3}}\right)-4 \pi^{2} \delta^{2}\right]^{\frac{1}{2}}, \quad(\mathrm{~g}-1) \mathrm{y}=\left[\Omega^{2}\left(\frac{\mathrm{g}_{1} \mathrm{~g}_{3}-\mathrm{g}_{2}^{2}}{\mathrm{~g}_{3}}\right)-4 \pi^{2} \delta^{2}\right]^{\frac{1}{2}}
$$

\section{Displacement of torsional mode}

The displacement of the composite poroelastic solid cylinder is determined by using the boundary conditions that the outer surface of composite cylinder is free from stress and at the interface displacements are equal. The normalized displacement $\mathrm{v}^{*}=\mathrm{v} /{ }_{1} \mathrm{v}\left(\right.$ where $\left.\mathrm{v}={ }_{1} \mathrm{v}+{ }_{2} \mathrm{v}\right)$ of torsional modes, after a long calculation, when $\omega>\left|\mathrm{kv}_{3}\right|$, reduce to

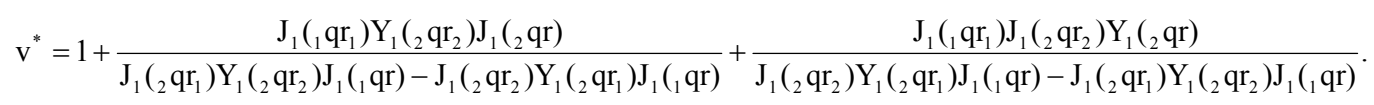

\section{First torsional mode}

If ${ }_{m} q^{2}(m=1,2)$ vanishes, i.e., $\omega={ }_{m} V_{3} k$, then the equation (5) will not yield to Bessel differential equation. Accordingly for composite poroelastic cylinders, Eq.(8) becomes

$$
{ }_{\mathrm{i}} \mathrm{q}^{2}=\mathrm{k}^{2}\left[\frac{\mathrm{m}}{\mathrm{m}_{\mathrm{i}} \mathrm{N}_{\mathrm{i}} \mathrm{K}} \mathrm{K}-1\right], \quad(\mathrm{i} \neq \mathrm{m}), \quad(\mathrm{i}, \mathrm{m}=1,2)
$$

where

$$
{ }_{\mathrm{i}} \mathrm{K}=\frac{{ }_{\mathrm{i}} \mathrm{M}{ }_{\mathrm{i}} \mathrm{X}-{ }_{\mathrm{i}} \mathrm{T}^{2}}{{ }_{\mathrm{i}} \mathrm{X}} \text {. }
$$

of eq.(5) is

$$
{ }_{1} \mathrm{~h}(\mathrm{r})=\mathrm{A}_{1} \mathrm{r}, \quad{ }_{2} \mathrm{~h}(\mathrm{r})=\mathrm{A}_{2} \mathrm{r} .
$$

where $\mathrm{A}_{1}$ and $\mathrm{A}_{2}$ are constants.

The boundary conditions are satisfied iff $A_{1}=A_{2}$. Hence as a special case when both materials of the composite poroelastic cylinder have same shear wave velocity, the first torsional mode exists uncoupled.

If the shear wave velocity of the core is different from that of the casing, then we consider two different cases.

a) When ${ }_{1} \mathrm{q}=0$, we have $\omega=\mathrm{k}\left({ }_{1} \mathrm{~V}_{3}\right)$ and 


$$
{ }_{2} \mathrm{q}^{2}=\mathrm{k}^{2}\left[\frac{{ }_{1} \mathrm{~N}_{2} \mathrm{~K}}{{ }_{2} \mathrm{~N}_{1} \mathrm{~K}}-1\right] \neq 0
$$

then the non-zero solution of equation (5) reduces to

$$
{ }_{1} \mathrm{~h}(\mathrm{r})=\mathrm{A}_{1} \mathrm{r}, \quad{ }_{2} \mathrm{~h}(\mathrm{r})=\mathrm{C}_{1} \mathrm{Z}_{1}\left({ }_{2} \mathrm{q} \mathrm{r}\right)+\mathrm{C}_{2} \mathrm{~W}_{1}\left({ }_{2} \mathrm{q} \mathrm{r}\right),
$$

where $A_{1}, C_{1}$ and $C_{2}$ are constants. Equation (24) with (9) gives the corresponding stresses. These stresses with the help of equations (24) and (3) when substituted into boundary conditions (10) give the frequency equation:

$$
\mathrm{C}_{11} \mathrm{C}_{22}-\mathrm{C}_{12} \mathrm{C}_{21}=0
$$

where $\mathrm{C}_{11}, \mathrm{C}_{12}, \mathrm{C}_{21}$ and $\mathrm{C}_{22}$ are defined in equation (14). Equation (25) will impose a restriction of the values of $\mathrm{k}$ for which this torsional mode exists uncoupled.

b) When ${ }_{2} \mathrm{q}=0$, we have $\omega=\mathrm{k}\left({ }_{2} \mathrm{~V}_{3}\right)$ and

$$
{ }_{1} \mathrm{q}^{2}=\mathrm{k}^{2}\left[\frac{{ }_{2} \mathrm{~N}_{1} \mathrm{~K}}{{ }_{1} \mathrm{~N}_{2} \mathrm{~K}}-1\right] \neq 0,
$$

then the non-zero solution of equation (5) is

$$
{ }_{1} \mathrm{~h}(\mathrm{r})=\mathrm{D}_{1} \mathrm{Z}_{1}\left({ }_{1} \mathrm{q} \mathrm{r}\right), \quad{ }_{2} \mathrm{~h}(\mathrm{r})=\mathrm{A}_{2} \mathrm{r} .
$$

where $\mathrm{D}_{1}$ and $\mathrm{A}_{2}$ are constants. Eq.(26) with (9) gives the corresponding stresses. Such stresses with the help of (26) and (3) when transformed into boundary conditions (10) yields the frequency equation:

$$
\mathrm{C}_{23}=0 .
$$

where $\mathrm{C}_{23}$ is defined in (14). Equation (27) imposes a restriction on values of $\mathrm{k}$ for which this torsional mode exists uncoupled.

Therefore, it is concluded that with the exception of poroelastic cylinders made of one material having the same shear wave velocity a mode similar to the first torsional mode of simple poroelastic cylinder exists uncoupled in composite poroelastic cylinders only for certain values of wavelength. The phase velocity of this uncoupled mode in the absence of dissipation will be equal to

$$
\left(\frac{{ }_{1} \mathrm{~N}}{{ }_{1}}\right)^{\frac{1}{2}}, \quad\left(\frac{{ }_{2} \mathrm{~N}}{{ }_{2} \mathrm{~K}}\right)^{\frac{1}{2}}
$$

depending on whether the values of wavelength satisfy equation $(25)$ or $(27)$ respectively, where ${ }_{i} \mathrm{~K}(\mathrm{i}=1,2)$ is defined in $(22)$.

\section{Special cases}

The composite poroelastic solid cylinder will reduce to poroelastic solid cylinder and hollow poroelastic cylinder depending on the poroelastic constants of the core, discussed below:

\subsection{Poroelastic solid cylinder:}

When the poroelastic constants of the two materials of the composite cylinder are same, the composite cylinder will become a solid cylinder made of one material. In this case let ${ }_{2} \mathrm{~N}={ }_{1} \mathrm{~N}=\mathrm{N},{ }_{2} \mathrm{q}={ }_{1} \mathrm{q}=\mathrm{q}$. The frequency equation of torsional vibrations (13) of a composite poroelastic cylinder when $\omega>\left|\mathrm{kv}_{3}\right|$, reduces to

$$
\left|\mathrm{D}_{\mathrm{ij}}\right|=0, \quad(\mathrm{i}, \mathrm{j}=1,2,3)
$$

where 


$$
\begin{aligned}
& D_{11}=\frac{-2 N}{r_{2}} J_{1}\left(\mathrm{qr}_{2}\right)+\mathrm{N} \mathrm{qJ}_{0}\left(\mathrm{qr}_{2}\right), \\
& \mathrm{D}_{12}=\frac{-2 \mathrm{~N}}{\mathrm{r}_{2}} \mathrm{Y}_{1}\left(\mathrm{qr}_{2}\right)+\mathrm{NqY}_{0}\left(\mathrm{qr}_{2}\right), \\
& \mathrm{D}_{23}=\frac{2 \mathrm{~N}}{\mathrm{r}_{1}} \mathrm{~J}_{1}\left(\mathrm{qr}_{1}\right)-\mathrm{N} \mathrm{qJ}_{0}\left(\mathrm{qr}_{1}\right), \quad \mathrm{D}_{13}=0, \\
& \mathrm{D}_{31}=-\mathrm{D}_{33}=\mathrm{J}_{1}\left(\mathrm{qr}_{1}\right), \quad \mathrm{D}_{32}=\mathrm{Y}_{1}\left(\mathrm{qr}_{1}\right) . \\
& \mathrm{D}_{21}, \mathrm{D}_{22} \text { are similar expressions as } \mathrm{D}_{11}, \mathrm{D}_{12} \text { with } \mathrm{r}_{2} \text { replaced by } \mathrm{r}_{1} .
\end{aligned}
$$

Equation (28) when expanded gives the product of two factors

$$
\mathrm{D}_{11}\left(\mathrm{D}_{21} \mathrm{D}_{32}-\mathrm{D}_{22} \mathrm{D}_{31}\right)=0 \text {. }
$$

The second factor is not equal to zero since it simplifies to $2 / \pi q r_{1}$ (Abramowitz and Stegun, 1965), while first factor reduces to

$$
\mathrm{J}_{2}\left(\mathrm{qr}_{2}\right)=0 .
$$

Equation (31) is the frequency equation of torsional vibrations of an infinite poroelastic solid cylinder discussed by Tajuddin and Sarma (1980).

\subsection{Poroelastic hollow cylinder:}

When the material constants of the core vanish, the composite poroelastic cylinder will become a hollow poroelastic cylinder. Setting ${ }_{1} \mathrm{~N}=0,{ }_{2} \mathrm{~N}=\mathrm{N},{ }_{2} \mathrm{q}=\mathrm{q}$ and ${ }_{1} \mathrm{q}={ }_{2} \mathrm{q}$ at the interface $\mathrm{r}=\mathrm{r}_{1}$, the frequency equation of torsional vibrations of a composite poroelastic cylinder (13) when $\omega>\left|\mathrm{kv}_{3}\right|$, reduces to

$$
\left|E_{i j}\right|=0, \quad(i, j=1,2,3)
$$

where

$$
\begin{aligned}
& \mathrm{E}_{11}=\frac{-2 \mathrm{~N}}{\mathrm{r}_{2}} \mathrm{~J}_{1}\left(\mathrm{qr}_{2}\right)+\mathrm{N} \mathrm{qJ}_{0}\left(\mathrm{qr}_{2}\right), \\
& \mathrm{E}_{12}=\frac{-2 \mathrm{~N}}{\mathrm{r}_{2}} \mathrm{Y}_{1}\left(\mathrm{qr}_{2}\right)+\mathrm{N} \mathrm{qY}_{0}\left(\mathrm{qr}_{2}\right), \\
& \mathrm{E}_{13}=0, \quad \mathrm{E}_{23}=0, \\
& \mathrm{E}_{31}=-\mathrm{E}_{33}=\mathrm{J}_{1}\left(\mathrm{qr}_{1}\right), \quad \mathrm{E}_{32}=\mathrm{Y}_{1}\left(\mathrm{qr}_{1}\right), \\
& \mathrm{E}_{21}, \mathrm{E}_{22} \text { are similar expressions as } \mathrm{E}_{11}, \mathrm{E}_{12} \text { with } \mathrm{r}_{2} \text { replaced by } \mathrm{r}_{1} .
\end{aligned}
$$

Expanding equation (32) and using the well-known Bessel functions recursion relations (Abramowitz and Stegun, 1965), it reduces to

$$
J_{2}\left(q r_{2}\right) Y_{2}\left(q r_{1}\right)-J_{2}\left(q r_{1}\right) Y_{2}\left(q r_{2}\right)=0
$$


Equation (34) is the frequency equation of torsional vibrations of hollow poroelastic cylinders of infinite extent discussed by Tajuddin and Ahmed Shah (2007).

\section{Numerical discussion}

The non-dimensional frequency equation related to torsional vibrations of a composite poroelastic cylinder, Eq.(18) is solved to determine non-dimensional frequency as a function of ratio of thickness of the casing to wavelength for two types of composite poroelastic cylinders, namely composite cylinder-I and composite cylinder-II. Composite cylinder-I consists of the core made of sandstone saturated with water (Yew and Jogi, 1976) and the casing made of sandstone saturated with kerosene (Fatt, 1959); while in composite cylinder-II, the core is made of sandstone saturated with kerosene and the casing with sandstone saturated with water. The materials chosen are just opposite in characteristic phenomenon. It is also intended to examine the effect of non-polar and polar fluid. The physical parameters of these composite cylinders are given under in Table-I.

Table-I. Material parameters

\begin{tabular}{|c|c|c|c|c|c|c|c|}
\hline Material Parameter & $\mathrm{d}_{1}$ & $\mathrm{~d}_{2}$ & $\mathrm{~d}_{3}$ & $\mathrm{~g}_{1}$ & $\mathrm{~g}_{2}$ & $\mathrm{~g}_{3}$ & $\mathrm{~d}$ \\
\hline Composite Cylinder-I & 0.887 & -0.001 & 0.099 & 0.877 & 0 & 0.123 & 0.30 \\
\hline Composite Cylinder-II & 0.891 & 0 & 0.125 & 0.901 & -0.001 & 0.101 & 3.33 \\
\hline
\end{tabular}

For a given material, the frequency equation (18) constitutes the relation between the non-dimensional frequency $(\Omega)$ and the ratio of thickness of the casing to wavelength $\mathrm{h} / \mathrm{L}(=\delta)$. $\delta$ take all the values between 0 and 1 including 0 and 1 . The values of $\mathrm{g}$ are taken as 1.01 and 4 which represent thin and thick casing respectively, of the solid composite poroelastic cylinder. A number of roots are obtained each describing a mode of vibration. Variation of frequency $\Omega$ is presented as a function of $\delta$ for composite cylinders-I and II having thin casing in Fig.1. Fig.1 shows that second and third modes have maximum frequency for composite cylinder-II at $\delta=0.8$ and minimum at $\delta=0.4$. Also frequency for composite cylinder-II is more than composite cylinder-I in

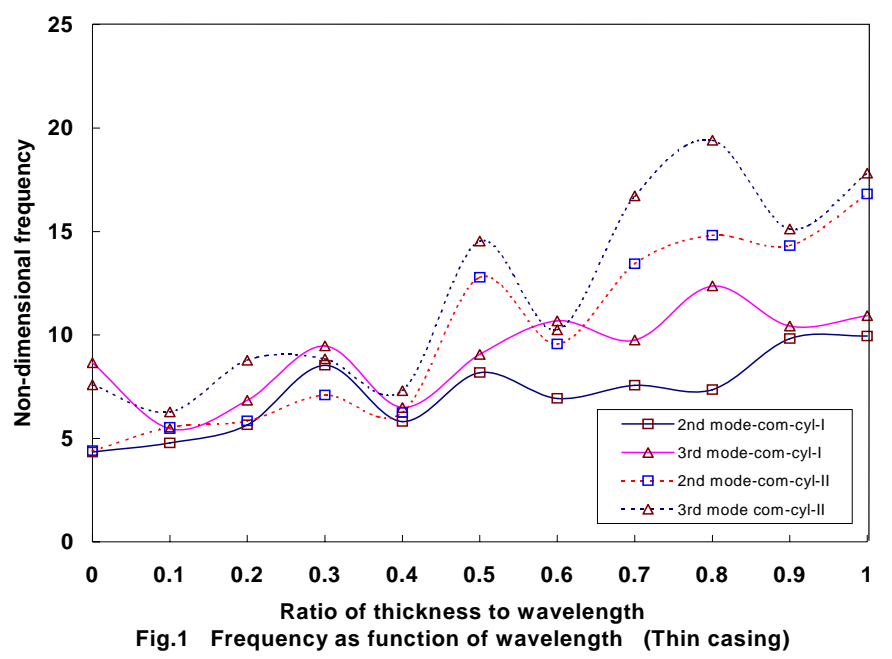

$0.4 \leq \delta<0.6$ and $0.6<\delta \leq 1$, but at $\delta=0.6$ the frequency is minimum.

Fig.2 shows the variation of frequency $\Omega$ versus $\delta$, of composite cylinders-I and II, having thick casing. It is clear that as $\delta$ increases, the frequency increases for both the composite cylinders, for second and third modes. Frequency for composite cylinderII is more than that of composite cylinder-I. Normalized displacements are shown in Fig. 3 for the above mentioned two composite poroelastic cylinders with thick casing and $\delta=0.1$, for second torsional mode. 


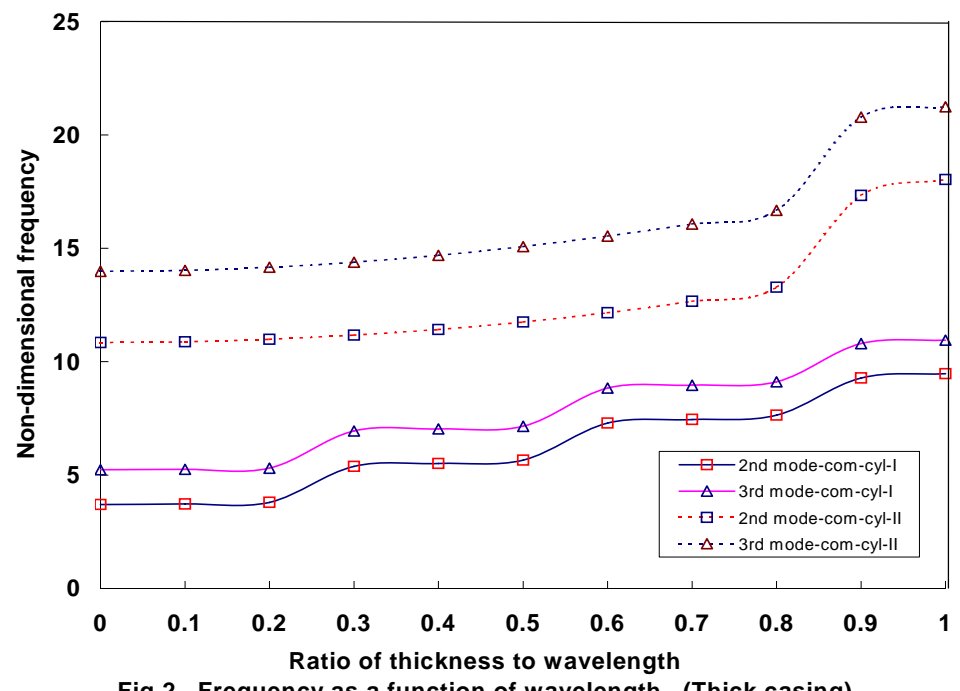

Fig.2 Frequency as a function of wavelength (Thick casing)

Similarly in Fig.4, the normalized displacement is represented for third torsional mode. Figs.3 and 4 shows that these displacements are non-linear.

Fig-5 shows the frequency of composite poroelastic cylinders when the wavelengths are large for second and third modes. These

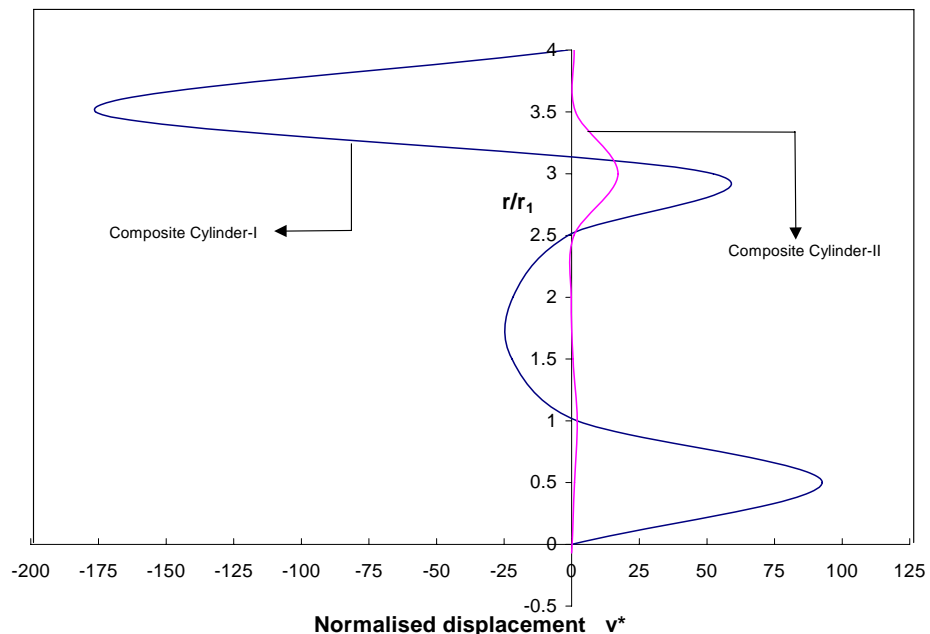

Fig.3 Displacement as a function of $r / r_{1}$ (Second torsional mode)

Thick casing $(\mathrm{r} 2=4 * \mathrm{r} 1)$ and $\delta=0.1$

modes have minimum frequency at $\delta=0.04$ and 0.06 and maximum at $\delta=0.05$. Fig. 5 shows that the frequency of second torsional mode is same for two above mentioned composite cylinders in $0 \leq \delta \leq 0.01$, while this is not true for the frequency of third torsional mode. 


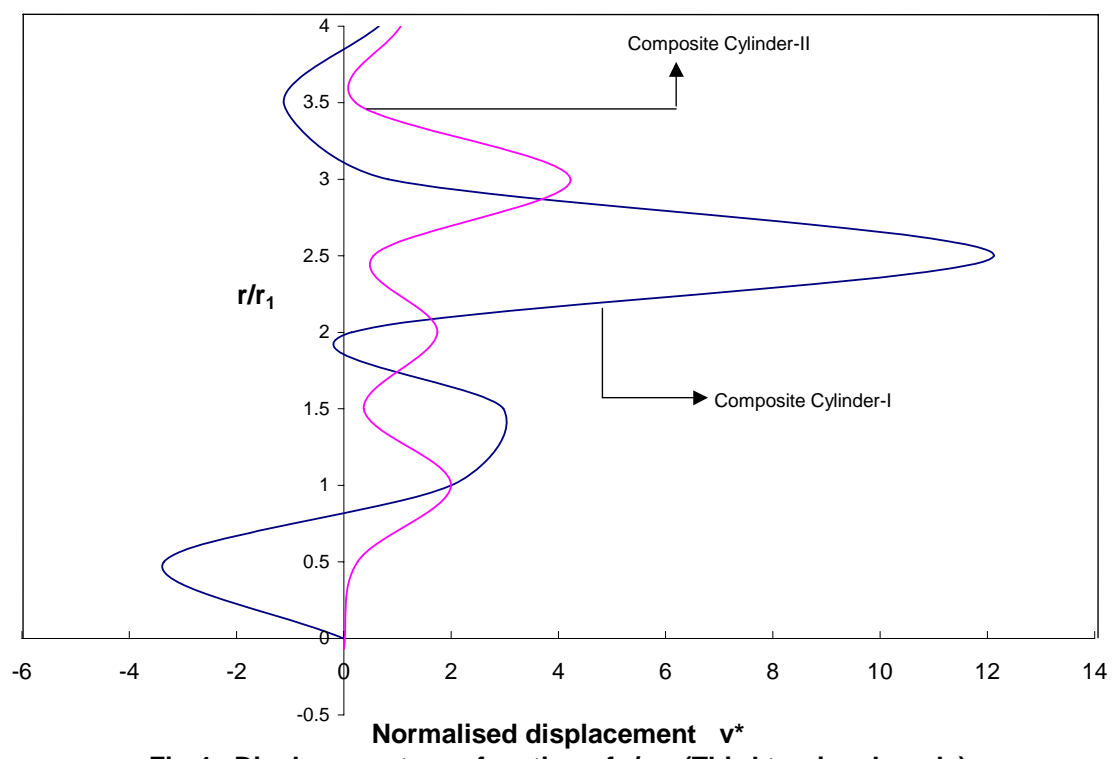

Fig.4 Displacement as a function of $r / r_{1}$ (Third torsional mode)

Thick casing $(\mathrm{r} 2=4 * \mathrm{r} 1)$ and $\delta=0.1$

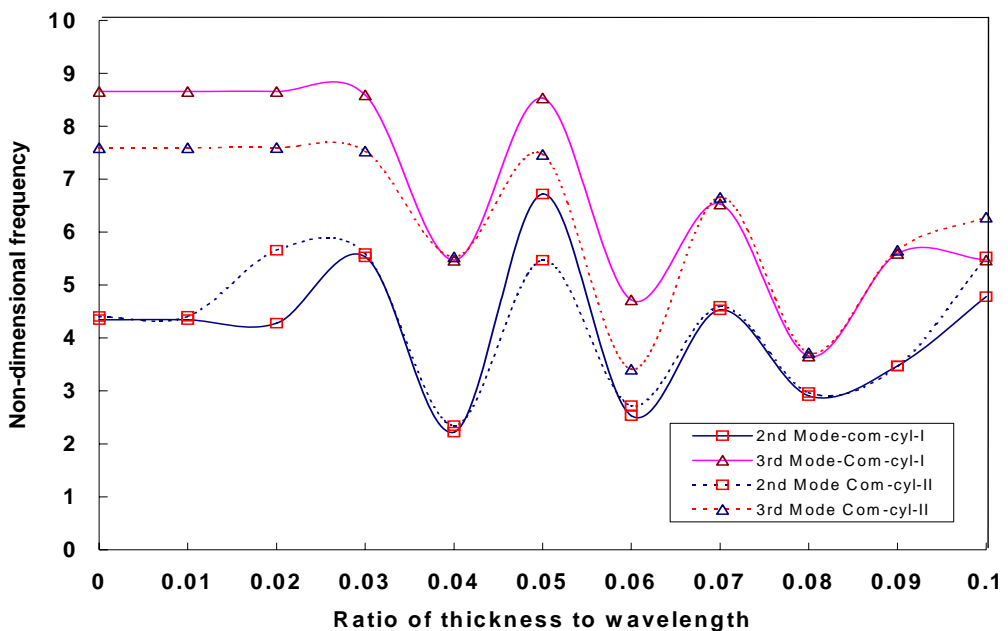

Fig.5 Frequency as a function of wavelength (Large wavelength, thin casing)

\section{Concluding remarks}

The investigation of torsional vibrations of composite poroelastic cylinders in case of thin and thick casing has lead to the following conclusion:

1. For the tested cases, the motion is coupled in the core and the casing of the composite poroelastic cylinders.

2. If the shear wave velocity is same in the core and the casing, the first torsional mode exists uncoupled.

3. The frequency for composite cylinder-I for thin casing is higher than that of corresponding modes of thick casing.

4. For the tested cases, the frequency of poroelastic composite cylinder-II is higher than that of poroelastic composite cylinder-I. This phenomenon is not true when the wavelength is large. 
5. The variation of normalized displacement is more for composite cylinder-I than that of composite cylinder-II.

6. For the tested cases, the frequency and the displacements are non-linear.

\section{Nomenclature}

$\begin{array}{ll}(\mathrm{r}, \theta, \mathrm{z}) & \text { Cylindrical polar coordinates } \\ \overrightarrow{\mathrm{u}} & \text { Solid displacement } \\ \overrightarrow{\mathrm{U}} & \text { Liquid displacement } \\ \mathrm{r}_{1} & \text { Radius of core (inner cylinder) } \\ \mathrm{r}_{2} & \text { Outer radius of casing (outer cylindrical shell) } \\ \mathrm{e} & \text { Dilatation of solid } \\ \epsilon & \text { Dilatation of liquid } \\ \nabla^{2} & \text { Laplace operator in cylindrical polar coordinates } \\ \mathrm{b} & \text { Dissipation } \\ \sigma_{\mathrm{ij}} & \text { Stresses } \\ \mathrm{s} & \text { Liquid pressure } \\ \mathrm{k} & \text { Wavenumber }\end{array}$

A, N, Q, R Poroelastic constants

$\tau, \beta, \eta \quad$ Mass coefficients

$\Delta=\frac{\mathrm{d}^{2}}{\mathrm{dr}^{2}}+\frac{1}{\mathrm{r}} \frac{\mathrm{d}}{\mathrm{dr}}-\frac{1}{\mathrm{r}^{2}}-\mathrm{k}^{2}$

$\mathrm{J}_{\mathrm{n}}(\mathrm{x}), \mathrm{I}_{\mathrm{n}}(\mathrm{x}) \quad$ Bessel function and modified Bessel function of first kind of order $\mathrm{n}$ and argument $\mathrm{x}$

$\mathrm{Y}_{\mathrm{n}}(\mathrm{x}), \mathrm{K}_{\mathrm{n}}(\mathrm{x}) \quad$ Bessel function and modified Bessel function of second kind of order $\mathrm{n}$ and argument $\mathrm{x}$

$\mathrm{V}_{3} \quad$ Shear wave velocity

$\omega \quad$ Circular frequency

$\delta \quad$ Ratio of thickness of casing to wavelength

$\Omega \quad$ Non-dimensional frequency

\section{Acknowledgement}

The authors are thankful to the reviewers for useful suggestions.

\section{References}

Abramowitz, A., Stegun, I.A., 1965. Handbook of mathematical functions, National Bureau of Standards, Washington.

Armenakas, A.E., 1965. Torsional waves in composite rods, J.Acoust.Soc.Am., Vol.38, pp.439-446.

Biot, M.A., 1956. Theory of propagation of elastic waves in fluid-saturated porous solid, J.Acoust.Soc.Am., Vol.28, pp.168-178.

Chao, G., Smeulders, D.M.J., and van Dongen, M.E.H., 2004. Shock-induced borehole waves in porous formations: Theory and experiments, J.Acoust.Soc.Am., Vol.116, pp.693-702.

Coussy O., Dormieux L., Detournay E., 1998. From mixture theory to biot's approach for porous media, Int.Journal of Solids and Structures., Vol.35, pp.4619-4635.

Degrande, G., De Roeck, G., Van Den Broeck, P., Smeulders, D., 1998. Wave propagation in layered dry, saturated and unsaturated poroelastic media, Int.Journal of Solids and Structures., Vol.35, pp.4753-4778.

Fatt, I., 1959. The Biot-Willis elastic coefficients for a sandstone, J.Appl.Mech., Vol.26, pp.296-297.

Gazis, D.C., 1958. Exact analysis of plane-strain vibrations of thick-walled hollow cylinders, J.Acoust.Soc.Am., Vol.30, pp.786794.

Gazis, D.C., 1959. Three-dimensional investigation of the propagation of waves in hollow circular cylinders, I., Analytical foundation, J.Acoust.Soc.Am., Vol.31, pp.568-573.

Gelinsky, S., Shapiro, S.A., Muller, T., Gurevich, B., 1998. Dynamic poroelasticity of thinly layered structures, Int.Journal of Solids and Structures., Vol.35, pp.4739-4751.

Malla Reddy, P., Tajuddin, M., 2003. Edge waves in poroelastic plate under plane-stress conditions, J.Acoust.Soc.Am., Vol.114, pp.185-193.

Malla Reddy, P., Tajuddin, M., 2006. Cylindrical stress waves in poroelastic flat slabs, Journal of Mechanics., Vol.22, pp.161165. 
McNiven, H.D., Sackman, J.L., Shah, A.H., 1963. Dispersion of axially symmetric waves in composite elastic rods, J.Acoust.Soc.Am., Vol.35, pp.1602-1609.

Tajuddin, M., Sarma, K.S., 1980. Torsional vibrations of poroelastic cylinders, Trans.ASME, J.Appl.Mech., Vol.47, pp.214-216.

Tajuddin, M., 1982. Torsional vibrations of finite composite poroelastic cylinders, Indian.J.pure and Appl.Math., Vol.13, pp.375-381.

Tajuddin, M., Ahmed Shah, S., 2006. Circumferential waves of infinite hollow poroelastic cylinders, Trans.ASME, J.Appl.Mech., Vol.73, pp.705-708.

Tajuddin, M., Ahmed Shah, S., 2007. On torsional vibrations of infinite hollow poroelastic cylinders, Journal of Mechanics of Materials and Structures, Vol.2, pp.189-200.

Wisse, C.J., Smeulders, D.M.J., van Dongen, M.E.H., Chao, G., 2002. Guided wave modes in porous cylinders: Experimental results, J.Acoust.Soc.Am., Vol.112, pp.890-895.

Yeheskel, O., Tevet, O., 2000. A new assessment method for the bulk modulus and the Poisson's ratio of porous ceramics, Journal of Testing and Evaluation, Vol.28, pp.189-198.

Yew, C.H., Jogi, P.N., 1976. Study of wave motions in fluid-saturated porous rocks, J.Acoust.Soc.Am., Vol.60, pp.2-8.

\section{Biographical notes}

Dr. M. Tajuddin is a Professor in the Department of Mathematics Osmania University, Hyderabad, India. He has more than 30 years of experience in teaching and research. His area of research includes wave phenomena aspects in elastic porous media. He has published more than forty papers in referred national and international journals. He has also presented several research articles in national and international conferences. He is currently dealing with a project sponsored by university grants commission New Delhi.

Dr.S.Ahmed Shah is a Professor in the Department of Mathematics, Deccan College of Engineering and Technology Hyderabad, India. He has more than 18 years of teaching experience. He published papers in referred national and international journals and has more than 10 years of research experience. His area of research includes stress wave propagation in poroelastic solids.

Received July 2010

Accepted October 2010

Final acceptance in revised form October 2010 